PRODUCTION

ENGINEERING ARCHIVES
2016, Vol. 10, No 1, pp 5-8

ISSN 2353-5156 (print version)

ISSN 2353-7779 (online version)

\title{
The assessment of quality of products using selected quality instruments
}

\begin{abstract}
Edyta Kardas ${ }^{1}$
${ }^{1}$ Czestochowa University of Technology, Faculty of Materials Processing Technology And Applied Physics, Ul. Dabrowskiego 69, 42-201 Czestochowa, Poland, (+48) 343250 753, ekonstan@wip.pcz.pl

Abstract The quality parameters of products should be controlled at every stage of the production process, since it allows detection of any problems even in the initial stages of production processes and removes their causes during manufacturing. Final control of products is intended to capture non-conforming products that did not go to the customers. The results of such controls should constantly be analysed. Such analysis can help to detect the most common problems, determine some dependences or identify the causes of such situations. A lot of different instruments that can support improvement of processes can be used for this kind of analysis. The paper presents the possibility of using some tools which can be utilized to support the analysis and assessment of quality of products at different stages of the production process. The quality analysis of exemplary products using selected quality methods and tolls is carried out. Metal sleeve, that is part of electronic control subassembly of anti-blocking system of ABS, which was the research component being studied.
\end{abstract}

Key words - quality, quality assessment, methods of quality managements, quality instruments, metal sleeve

\section{Introduction}

Quality of products is one of the factors determining customer satisfaction and profit for the company. For companies which work in the automotive industry, the quality of products has additional significance for customers. The quality of the produced component affects the quality, comfort and safety of use of vehicles, which has a significant impact on people's health and life. Production of repeatable products (products with the same level of quality parameters), which have the best parameters compatible with the specifications, standards and requirement of the customers, is very important for the companies (TORUŃSKI J. 2012, HAMROL A., MANTURA W. 2009). Continuous analysis of products at each stage of the production process, from assessment of quality of materials, through to the various stages of manufacturing to the control of products in stock, is one on the most important factors relevant to the quality of finished products (BORKOWSKI S., INGALDI M., JAGUSIAK-KoCIK M. 2014, INGALDI M. 2014, SYGUT P. 2015). The analysis of sleeve, that is part of electronic control subassembly of antiblocking system of ABS, was presented in this paper. This analysis was based on results from a manufacturing company of automotive industry operating in the region of Lodz. The assessment of the quality of the finished product was also presented. The research covers the period of 1 calendar year.

\section{Characteristics of the tested object}

The quality analysis of metal sleeve is presented in this paper. The appearance of this sleeve is presented in Fig. 1. 


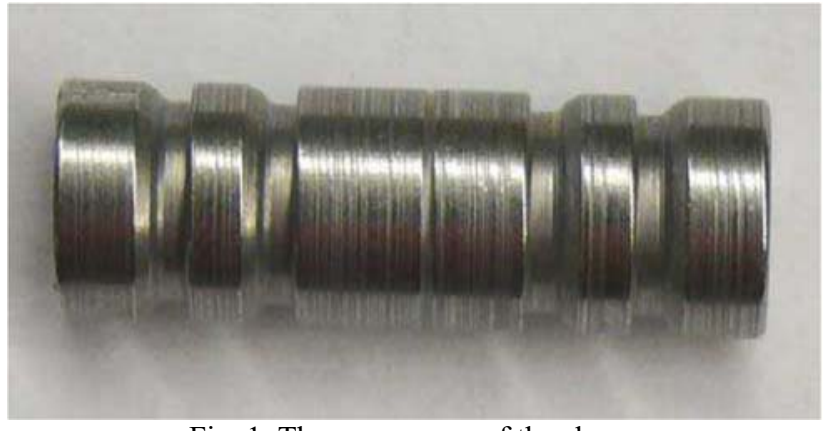

Fig. 1. The appearance of the sleeve Source: $[6,7]$

This sleeve is the part of braking system. This is the part of component of electronic control subassembly of anti-block system of ABS, which is presented in Fig. 2.

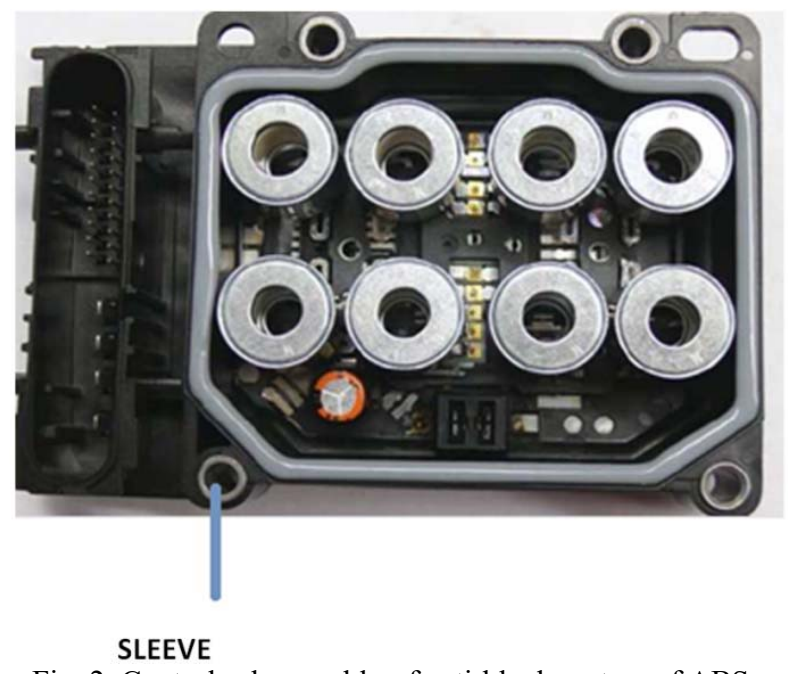

Fig. 2. Control subassembly of anti-block system of ABS Source: (KoZIEŃ A. 2011)

This sleeve has to be produced with the utmost accuracy and precision due to the fact that the ABS control system effects on safety of vehicle users.

\section{Methodology}

In order to assess the quality of finished products the following quality tools were used:

1. Pareto chart - quantitative analysis of nonconforming products was made, all defective products were divided into 10 groups and the most frequent non-conformance was identified.

2. Ishikawa's diagram - causes of the most frequent non-conformance were identified and were divided into 5 groups.
3. 5xWHY? method - one of causes of the most frequent non-conformance was analysed deeply.

4. SPC - statistical analysis was made for one of parameters connected with the most frequent nonconformance. Elements of this analysis were following: histogram, basic statistics, three sigma law, process performance indexes (Pp, Ppk), control chart.

\section{Pareto chart for non - conforming sleeves}

The Pareto chart of finished sleeves was made. Results used in the analysis covered 12 months of 1 calendar year. Ten of the most frequent non - conformances were observed in the research products:

- Dimensional error - wrong dimension, usually too short element,

- Material error - visible joining of mould during casting of material, which cannot be removed during treatment,

- No treatment - untreated product,

- Edge - protruding edge on the lateral surface of the sleeve,

- Notches - corrugated lateral surface inside the sleeve,

- Loose chips - chips inside the sleeve,

- Impressions - damages on the surface caused by tool outside the sleeve,

- Surface - surface defects inside the sleeve,

- Steps - corrugated lateral surface inside the sleeve,

- Damage - defects of the surface caused by inaccurate treatment.

The Pareto chart was made based on the results on the quantitative analysis of non - conformances. Diagram was presented in Fig. 3.

The Pareto chart (Fig. 3) showed that dimensional error was the most frequent non - conformance (almost $22 \%)$, than surface $(20 \%)$ and damages (18\%). These three non - conformances in total has an effect in $60 \%$ of all non - conforming sleeves. Non - conformances (loose chips, impressions, notches, material error) occurred in small amount of product were insignificant in point of view of production process. 


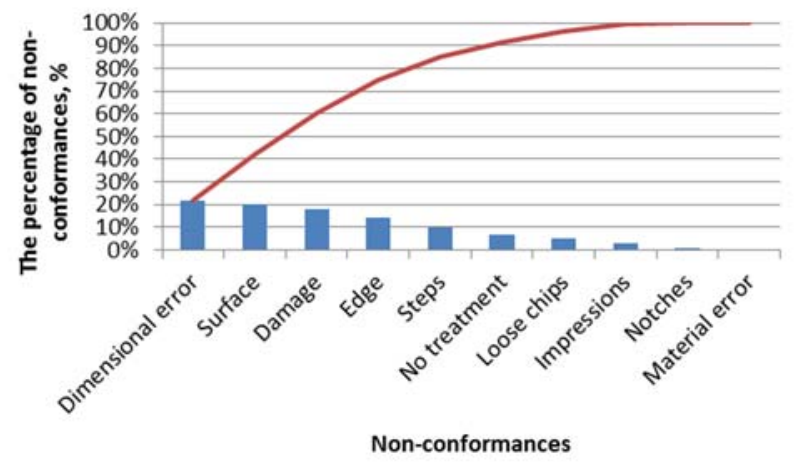

Fig. 3. Pareto chart of non - conformances Source: Own study based on (KARDAS E. 2013, KARDAS E. 2014)

\section{Ishikawa's diagram for causes of ap- pearing of non-conformance of dimen- sion of metal sleeve (short part)}

Using Ishikawa's diagram the analysis of causes of appearance of the most common non-conformance was made. It demonstrated all significant relations, which caused the problem of dimension (short part). Groups of the causes of this non-conformance using Ishikawa's diagram is presented in Figure 4.

Ishikawa's diagram presented in Figure 4 shows how the source of failure and malfunctioning of the process can be discovered and identified. In addition, it indicated essential relations among various reasons causing research non-conformance. The application of diagram enabled the identification and classification of causes of the issue and presentation of imperfections of the process.

\section{The analysis of selected reason of non- conformance of short part (chipping tool) for metal sleeve using $5 \times$ WHY? method}

After the Ishikawa's analysis, the method of $5 \times$ WHY? should be made in order to further identification of the problem and improving its quality. This analysis is presented in Table 1. The analysis of the causes associated with chipping tool was made.

$5 \times$ WHY? method showed how the causes of nonconformance - short part can be eliminated. The analysis of cutting tool showed that the roll of cam in the automatic lathe was deformed due to the low hardness of the used material.
Table 1. The analysis of selected reason of non-conformance, dimensional error of sleeve - short element (crushed tool), using method 5x WHY?

\begin{tabular}{|l|l|}
\hline \multicolumn{2}{|c|}{ Why did the problem occur? } \\
\hline Why? & Chipping cutting edge of the tool \\
\hline Why? & Vibrations transmitted form the tool post \\
\hline Why? & Unstable bringing the tool post to the material \\
\hline Why? & Roller of running cam has been deformed \\
\hline Why? & $\begin{array}{l}\text { Deformation of rolls caused due to the low } \\
\text { hardness of used material }\end{array}$ \\
\hline
\end{tabular}

Source: Own study based on (KARDAS E. 2013, KARDAS E. 2014)

\section{Summary}

The assessment of quality of products, especially in automotive industry, has great importance for customers due to their satisfaction and significant impact on people's health and life. Metal sleeve, which is part of braking system, was the product under study.

Based in the analysis, presented in this paper, it can be said that:

- There was no trend or periodical fluctuation in the amount of non - conforming products ${ }_{2}$ only small changes were observed. These changes can be caused mainly by various factors of the production process.

- Pareto chart showed that during study period ten non - conformances appeared. Three of them: dimensional error (almost 22\%), surface (20\%) and damage (18\%) were the most frequent and had the greatest importance for the quality of products.

- The use of Ishikawa's method presented all significant relations among various reasons that caused non-conformance occurring the most frequently - improper dimension of metal sleeve (short part). Diagram enabled the identification and classification of causes of this issue and indication of causes of imperfections of the process.

- $5 \mathrm{xWHY}$ ? method showed what was the primary cause of non-conformance - short part. During the analysis of cutting tool it turned out that the roll of cam in the automatic lathe was deformed due to the low hardness of the used material.

- Amount of non - conforming products is very low. During research period only 138 pieces of product were detected. Analysis shows that quali- 
ty of product is very high and performs requirements of customer. That small amount of non conforming products is the result of the quality control on every step of production process, what

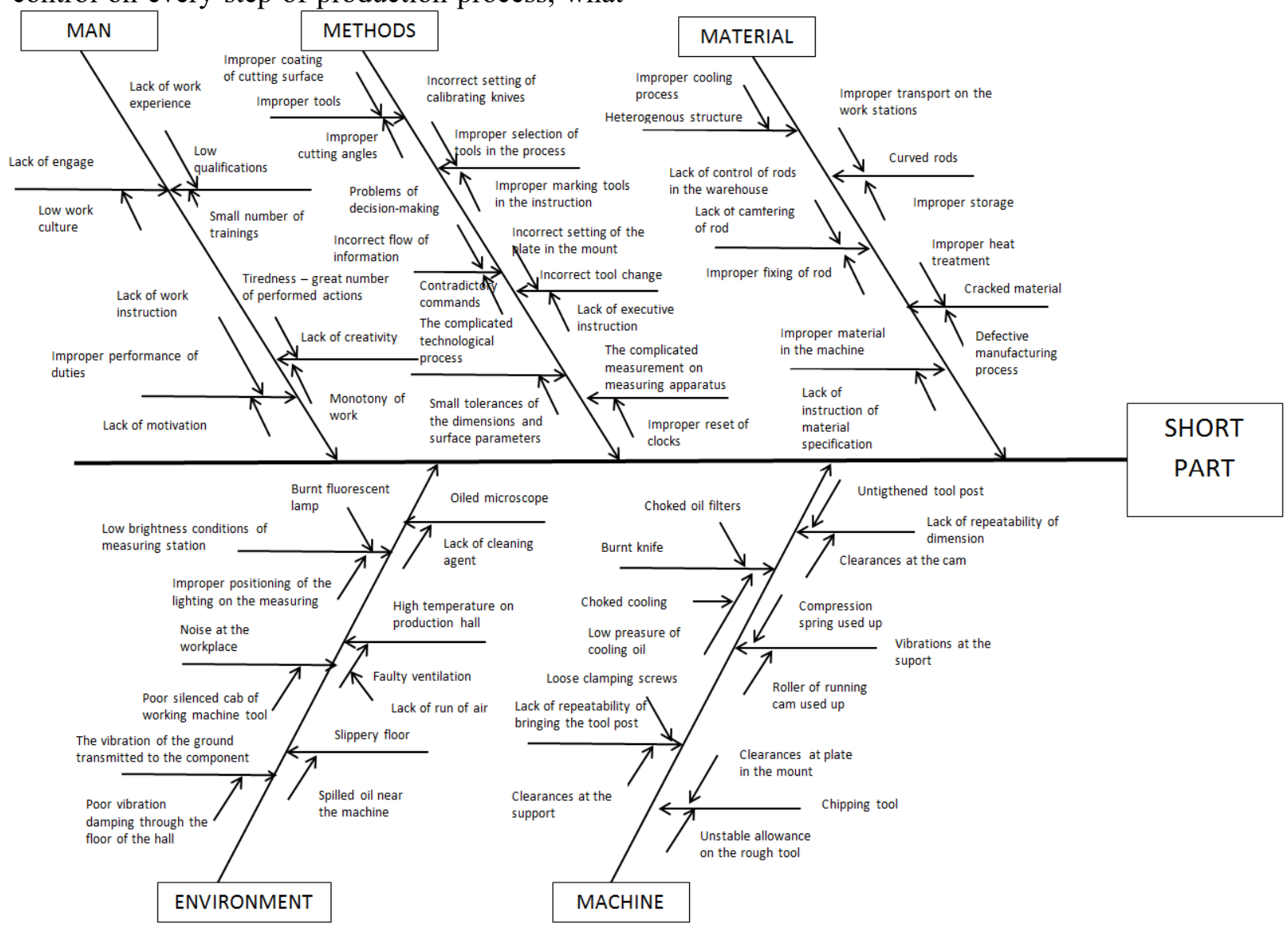

Fig. 4. The analysis of causes of dimensional error of sleeve (short element) Source: Own study based on (KARDAS E. 2013, KARDAS E. 2014)

\section{REFERENCES}

1. TORUŃSKI J. 2012. Quality management in the automotive industry, Scientific papers of the University of Natural Science and Humanities in Siedlce, Series: Administration and management, No 92/, pp. 23 - 32.

2. HAMROL A., MANTURA W. 2009. Quality analysis. Theory and practice, PWN, Warsaw.

3. BORKOWSKI S., INGALDI M., JAGUSIAK-KOCIK M. 2014. Quality analysis and technological portfolio in production of the metal screws, METAL 2014 - 23rd International Conference on Metallurgy and Materials, Conference Proceedings, pp. 1716-1722

4. INGALDI M. 2014. Analysis of the quality problems during production process of the stud frame of the stretching station, Production Engineering Archives, Vol. 2, No. 1, pp. 2-5 helps to detect even small error and prevent them to appear later. 